\title{
Cardiovascular risk factors of hypertension, smoking and obesity: Emerging concerns among Pathan and Persian young adults?
}

\author{
Hammad Shah*1, Afrasyab Altaf ${ }^{1}$, Momin Salahuddin ${ }^{1}$, Muneeb Ullah Jan ${ }^{2}$, Adnan Khan ${ }^{3}$ \\ Received: 30 Dec 2017 \\ Published: 24 Dec 2018
}

\section{Abstract}

Background: Hypertension was considered as a disease of the elderly but due to unhealthy dietary and lifestyle changes its incidence has increased in younger population. Smoking and obesity are emerging concerns the world is facing globally in younger age groups. This study is therefore aimed to identify these cardiovascular risk factors among Pathan and Persian young adults.

Methods: It was a cross-sectional study carried out at multiple undergraduate, postgraduate educational institutes and hospitals using non-probability convenient sampling among young adults aged between 15 to 40 years for a period of six months from Apr 1 st, 2017 to Sep 30th, 2017. Mean \pm SD was calculated for continuous variables and categorical variables were expressed as frequencies. Chi-square test and Fisher exact test were used for statistical analysis.

Results: A total of 708 subjects were included. Mean \pm SD age was $26.12 \pm 3.7$ years. Out of $708,300(42.37 \%)$ were smokers with 209 $(29.52 \%)$ active and $91(12.85 \%)$ passive smokers. Among smokers, $216(30.5 \%)$ were males while $84(11.87 \%)$ were females. A total of $432(61.02 \%)$ subjects were not doing any exercise, and $636(89.83 \%)$ were consuming junk food. A total of $165(23.3 \%)$ subjects were overweight, and $15(2.1 \%)$ were obese. Stage-1 hypertension was present in $72(10.2 \%)$, while $16(2.25 \%)$ subjects had stage-2 hypertension.

Conclusion: There is an increased prevalence of cardiovascular risk factors which includes hypertension, smoking, and obesity among Pathan and Persian young adults.

Keywords: Cardiovascular, Risk factors, Hypertension, Smoking, Obesity, Young adults

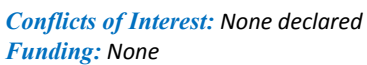

Cite this article as: Shah H, Altaf A, Salahuddin M, Ullah Jan M, Khan A. Cardiovascular risk factors of hypertension, smoking and obesity: Emerging concerns among Pathan and Persian young adults? Med J Islam Repub Iran. 2018 (24 Dec);32:129. https://doi.org/10.14196/mjiri.32.129

\section{Introduction}

Hypertension is a global public health concern. About one billion people are suffering from high blood pressure

Corresponding author: Dr Hammad Shah, drhammadshah@gmail.com

1. Cardiology Department, Rehman Medical Institute, Peshawar, Pakistan

2. Medicine Department, Khyber Teaching Hospital, Peshawar, Pakistan

3. Paediatric Department, Rehman Medical Institute, Peshawar, Pakistan which is causing a total of 7.5 million deaths (1). The hypertension is considered as the silent killer, because it is

$\uparrow$ What is "already known" in this topic:

Hypertension, obesity and smoking are already established causes of adverse cardiovascular events. Previously hypertension was considered as a disease of the elderly but now due to modernization, sedentary lifestyle, mushroom growth of fast food industry; increase use of in indoor gadgets and unhealthy dietary habits, obesity is becoming a global concern.

\section{$\rightarrow$ What this article adds:}

Due to increasing obesity and more inclination of young adults towards smoking, incidence of hypertension is increasing in younger age groups. This study will help in identification of these emerging concerns. Highlighting these adverse cardiovascular hazards will provide evidence for efforts to curb down and control these risk factors to which our community is highly ignorant. 
difficult to diagnose clinically and remains undetected before causing complications. It is the most common modifiable risk factor to decrease both mortality and morbidity. Although it is a disease of the elderly but an increasing number of younger people are becoming victims of silent undiagnosed hypertension (2). Due to different socioeconomic issues, psychological factors, unhealthy dietary habits, and sedentary lifestyle an increasing number of younger people are becoming hypertensive $(3,4)$. As it has numerous negative impacts on different vital organs of the body includin g heart, brain, kidneys, and eyes, therefore it is very important to diagnose it early to prevent unwanted complications (5).

Smoking has a positive linear relationship with hypertension mediated by inflammation (6). According to WHO statistics about 6 million people are killed every year by tobacco smoke, of which $10 \%$ are passive smokers (7). Elevated resting heart rate is a major cardiovascular risk factor and leading cause of mortality (8). Smoking decreases heart rate variability by affecting the autonomic nervous system, hence increasing both cardiovascular mortality and morbidity $(9,10)$. No effective legislation exists in our country to prevent younger population from hazards of smoking. With easy availability, lack of awareness and no legislation an increasing number of younger children and adults are becoming victims of smoking locally $(11,12)$.

Obesity and smoking are two emerging concerns the world is facing globally (13). Similar to smoking, obesity has a very paramount negative impact in developing hypertension and is a well-established risk factor (14-17). Obesity contributes to different hormonal imbalances and is a major cause of both mortality and morbidity (18). Use of technology and modernization is limiting our daily physical activities. Rapid growth of fast-food industry, increasing urbanization, and sedentary lifestyles are further making the people vulnerable to obesity.

Evidence from the aforementioned data identifies hypertension, smoking, and obesity as emerging concerns affecting the younger population, thereby making them prone to adverse cardiovascular events. This study was therefore aimed at identifying the prevalence of these cardiovascular risk factors among young adults of Pathan and Persian population. It will help in the early detection of these risk factors, and appropriate preventive measures will curb down both cardiovascular mortality and morbidity.

\section{Methods}

This study was carried out at Rehman Medical Institute Peshawar (RMI), Rehman Medical College Peshawar(RMC), Northwest General Hospital and Research Centre Peshawar (NWGH), Khyber Medical University Peshawar (KMU), Hayatabad Medical Complex Peshawar (HMC), Khyber Medical College Peshawar(KMC), Islamia College University Peshawar (ICUP), University of Engineering and Technology Peshawar (UET), University of Peshawar (UoP) and Agriculture University Peshawar (AUP) from Apr $1^{\text {st }}, 2017$ to Sep 30 ${ }^{\text {th }}, 2017$ a period of six months.

Subjects were identified via non-probability convenient sampling. The sample size was calculated as 308 , with
$95 \%$ confidence interval according to WHO formula:

$$
\text { Sample size }=\frac{\frac{z^{2} \times p(1-p)}{e^{2}}}{1+\left(\frac{z^{2} \times p(1-p)}{e^{2} N}\right)}
$$

however, we included more subjects from multiple centers, to further increase the authenticity of our results. A total of 708 subjects were included in the study population from 10 different centers. It included those who gave consent for it and had age between 15 to 40 years, belonging to both sexes (male and female), different ethnic background, socioeconomic status, and geographical location. Those subjects who did not give written consent, were taking alpha agonists, had nasal obstruction, were suffering from chronic kidney disease, diabetes, pre-ductal or post-ductal coarctation of aorta, renal artery stenosis, gestation hypertension, pre-eclampsia, eclampsia, thyroid hormone abnormalities, pheochromocytoma were excluded from the study.

Data was collected using a printed performa. It was translated to mother tongue language for those who did not understand English or were Afghans with the help of local translators.

Blood pressure (BP) was determined using a portable mercury sphygmomanometer, (Certeza CR 2002- San Juan, Philippines) in sitting position, which was standardized with an arterial BP monitor (iMEC-12: Mindray North America, United States) of RMI operation theatre. Three different readings were taken using both hands each 10 minutes of rest apart in sitting position. Average of all the three readings was documented as blood pressure of the subject. Body Mass Index (BMI) was calculated by dividing weight in kilogram $(\mathrm{kg})$ over height in meter square $\left(\mathrm{m}^{2}\right)$. Weight was determined using the portable weight machine (Westpoint 7007-United States) without shoes and extra upper over the clothes. Height was measured in meters, using a measuring tape and portable stadiometer (seca 213-Hamburg Germany), from heel to vertex of the skull without shoes.

Informed written consent was taken from all individuals. Confidentiality of patients was ensured. This study was approved by research and ethics committee of RMI, Peshawar, Pakistan and abided by the declaration of Helsinki.

Data was analyzed using SPSS 20. The Shapiro-Wilk test was used to assess the normality in the data. Continuous variables were measured as mean \pm standard deviation (SD). Categorical variables like gender, smoking, junk food intake, exercise activity, BMI, systolic and diastolic blood pressure were expressed as frequencies. Chi-square test was applied to determine the statistical significance between categorical variables. The Fisher exact test was used where sample size was smaller. A p-valve less than 0.05 was considered significant.

\section{Operational Definitions}

Type-1 Hypertension was defined as a systolic blood pressure of $140-159 \mathrm{mmHg}$ while type-II hypertension was defined as $>160 \mathrm{mmHg}$ on a mercury sphygmomanometer (19).

Active Smoking was defined as exposure to tobacco 
smoke while puffing the cigarette by himself/herself. Passive smoking was defined as exposure to tobacco smoke daily while not puffing by himself/herself $(20,21)$.

Obesity was determined by evaluating the BMI which was calculated by dividing the weight of the person in kilogram with the height of the person in meters. A BMI of $>30$ was considered as obese while BMI between 25-30 was considered as overweight while BMI of 20-24.9 was considered as normal weight. A BMI of $<20$ was considered as underweight (22).

Active lifestyle was defined as at least 20 minutes of brisk walk 5 times a week (23).

\section{Results}

A total of 708 subjects were included in the study, including $465(62.7 \%)$ males and $243(37.3 \%)$ females. Mean age was $26.12 \pm 3.7$ years. $300(42.37 \%)$ subjects were smokers, including 209 (29.51\%) active smokers and 91 (12.79\%) passive smokers. Among smokers, 216 (30.5\%) were males and $84(11.87 \%)$ females as shown in Figure 1.

Junk food intake was observed daily in 54(7.6\%), on alternate days in 102(14.4\%), twice per week in $276(39 \%)$, weekly in $138(19.5 \%)$ and fortnightly in $66(9.3 \%)$ making $636(89.8 \%)$ subjects of the total included as shown in Figure 2.

A total of $432(61 \%)$ subjects were not doing any sort of exercises. In the remaining $276(39 \%)$ only $36(5.1 \%)$ were doing daily exercise, $50(7 \%)$ doing it on alternate days, $88(12.5 \%)$ doing it only twice per week, $84(11.9 \%)$ doing it only once per week while $18(2.5 \%)$ had other trends as shown in Figure 2.

Both these unhealthy dietary and lifestyle factors are biggest contributors to obesity. Calculating the BMI, $151(21.2 \%)$ of the subjects were overweight and $15(2.1 \%)$ were obese. A total of 513(72.5\%) had normal and $30(4.2 \%)$ had low BMI as shown in Table 1.

Among 708 patients, 30 (4.2\%) had a BP of lower than $100 / 60 \mathrm{mmHg}$. Normal BP were obtained in 458 (64.6\%) of

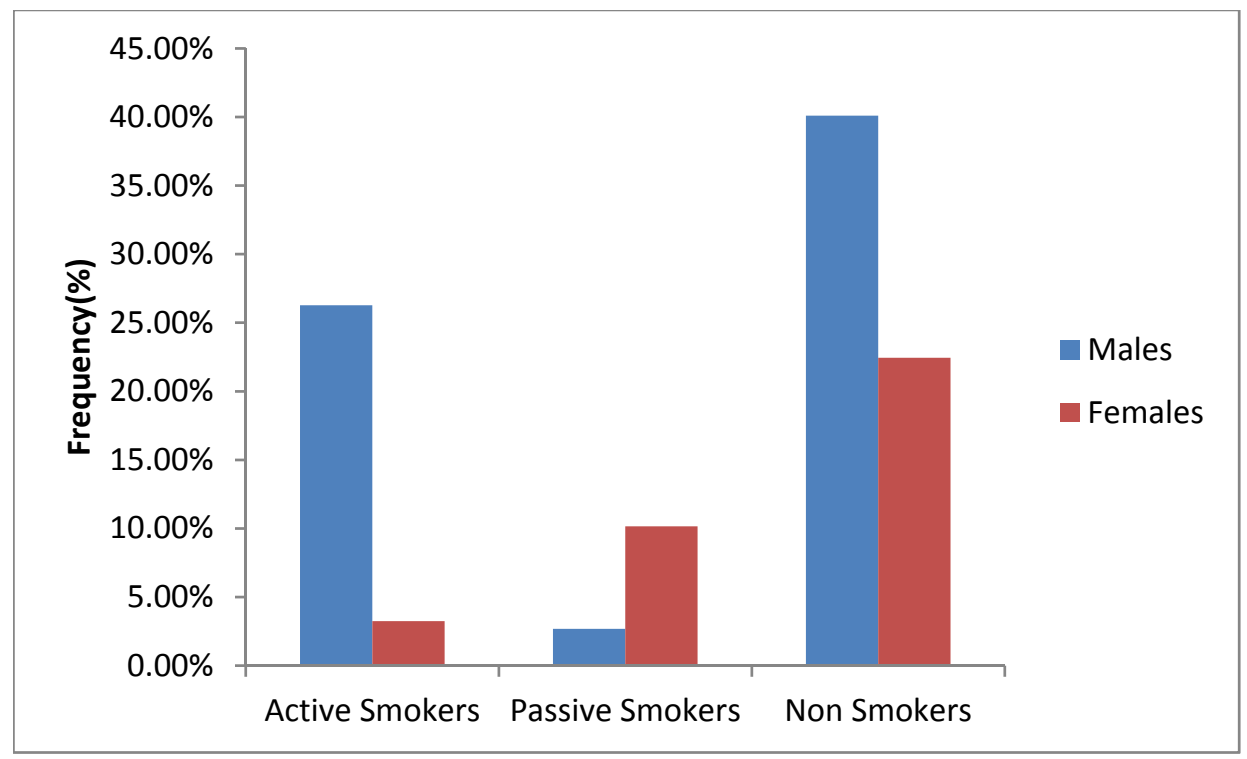

Fig. 1. Smokers (Active and Passive) and non-smokers frequency distribution by gender

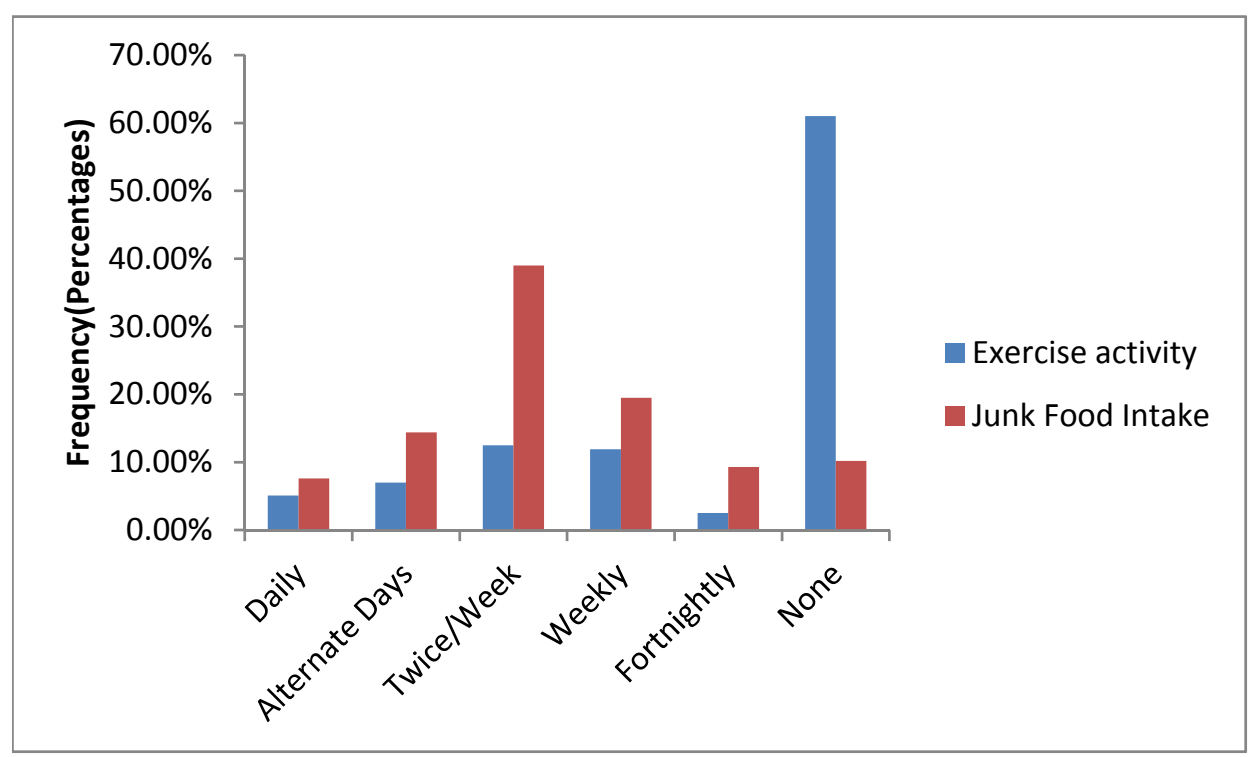

Fig. 2. Frequency of exercise activity and junk food intake 


\begin{tabular}{|c|c|c|}
\hline BMI category & \multicolumn{2}{|c|}{$\begin{array}{c}\text { Frequency } \\
\mathrm{N}(\%)\end{array}$} \\
\hline Underweight (BMI<20kg/m2) & \multicolumn{2}{|c|}{$30(4.2 \%)$} \\
\hline Normal (BMI 20-24.9kg/m2) & \multicolumn{2}{|c|}{$513(72.5 \%)$} \\
\hline Overweight(BMI 25-29.9 kg/m2) & \multicolumn{2}{|c|}{$151(21.2 \%)$} \\
\hline Obese $(\mathrm{BMI}>30 \mathrm{~kg} / \mathrm{m} 2)$ & \multicolumn{2}{|c|}{$15(2.1 \%)$} \\
\hline \multicolumn{3}{|l|}{ able 2. Frequency of systolic and diastolic blood } \\
\hline $\begin{array}{l}\text { Systolic BP } \\
(\mathrm{mmHg})\end{array}$ & $\begin{array}{l}\text { Diastolic BP } \\
(\mathrm{mmHg})\end{array}$ & $\begin{array}{l}\text { Frequency } \\
\text { N (\%) }\end{array}$ \\
\hline $30(4.2 \%)$ & $<60$ & $30(4.2 \%)$ \\
\hline $290(40.9 \%)$ & $60-69$ & $290(40.9 \%)$ \\
\hline $168(23.7 \%)$ & $70-79$ & $168(23.7 \%)$ \\
\hline $132(18.6 \%)$ & $80-89$ & $132(18.6 \%)$ \\
\hline $72(10.2 \%)$ & $90-99$ & $72(10.2 \%)$ \\
\hline $16(2.2 \%)$ & $>100$ & $16(2.2 \%)$ \\
\hline
\end{tabular}

subjects. However, $132(18.6 \%)$ of the subjects were in the pre-hypertensive stage. A total of $72(10.2 \%)$ subjects suffered from stage-I hypertension, and stage-II hypertension was observed in $16(2.25 \%)$ subjects as shown in Table 2.

\section{Discussion}

Our study showed that $42.37 \%$ of young adults are smokers which was comparable with a study done on young adults of Karachi, which showed 39\% smokers. They also established several factors responsible for increasing smoking trend in young adults. Family smoking behavior and close friends who smoke increase the likelihood of smoking in subjects (24).

In our study smoking was more common in male subjects $(30.5 \%)$ as compared to females $(11.87 \%)$. However females were more vulnerable to passive smoking as compared to males. Similar propensity was observed in another population-based study in which trends of smoking is increasing in men as compared to women (25). According to WHO statistics, $40 \%$ of men around the world are smokers as compared to $9 \%$ women, but women are more prone to passive smoking accounting for $64 \%$ of the passive smokers globally (26). Besides different social, psychological and genetic norms, easy availability and lack of effective legislation are major causes of increased prevalence of smoking in male subjects. However the false belief that it causes weight loss is a major cause of the increasing trend of smoking in young girls.

In our study, about $23.3 \%$ of young adults had above normal weights compared to the calculated appropriate weights for their height. There is an increasing concern about obesity throughout the world, although the prevalence of becoming overweight and obese has increased tremendously (27). Our results showed that $61 \%$ of young adults did not perform any sort of exercises and $89.8 \%$ of subjects were consuming junk food. Sedentary lifestyle and lack of physical activity were identified as the biggest contributors to obesity by different studies $(28,29)$. Similarly significant correlation between fast food intake and body weight has been established (30). Both these unhealthy dietary and lifestyle habits are biggest contributors to gaining weight.

Our results showed that $10.2 \%$ of subjects are suffering from stage- 1 and $2.2 \%$ subjects from stage- 2 hypertension. Different studies have established that active individuals and athletes are free from hypertension but obesity, unhealthy dietary habits, and sedentary lifestyle are the biggest factors contributing to hypertension $(31,32)$.

\section{Limitations}

Considering the cross-sectional design of this study we were not able to predict the true prevalence in the general population. However, it will serve as a base for further population-based epidemiological studies to bring into limelight the impact of increased prevalence of cardiovascular risk factors such as hypertension, smoking, and obesity in young adults.

\section{Conclusion}

Active smoking is more common in young males while young females are victims of passive smoking. Unhealthy lifestyle, dietary habits and lack of physical activities are contributing to the increase in obesity. These factors lead to an increase in the prevalence of hypertension in young adults of Pathan and Persian population.

\section{Recommendation}

Efforts should be made to curb down the increase in smoking trend, by raising awareness of general public about its hazards. Physical activities, exercise, and healthy dietary habits should be encouraged. Screening for hypertension should be started at younger ages.

\section{Conflict of Interest}

We all authors certify that we have no conflict of interest including special financial interest and association relevant to the subject matter or material discussed in the manuscript.

\section{References}

1. World Health Organization (WHO). A Global Brief on Hypertension: Silent Killer, Global Public Health Crisis; 2013. Available from: http://www.thehealthwell.info/node/466541.

2. Lauzurica LZ, Izquierdo JQ, Vinuesa JM, Más JR. Prevalence of Hypertensión and Associated Factors in Population Aged 16 to 90 Years Old in Valencia Region, Spain. Rev Esp Salud Publica. 2016 Apr 1;90:1-11. 
3. Khajedaluee M, Hassannia T, Rezaee A, Ziadi M, Dadgarmoghaddam M. The prevalence of hypertension and its relationship with demographic factors, biochemical, and anthropometric indicators: A population-based study. ARYA Atheroscler. 2016;12(6):259-265.

4. Aurangzai B, Saif SUD, Rehman FU. Risk factors for hypertension in a rural dwelling. JRMC. 2013;17(1):33-35

5. Ramanathan AS, Senguttuvan P, Prakash V, Vengadesan A, Padmaraj R. Budding adult hypertensives with modifiable risk factors: "Catch them young". J Fam Commun Med. 2016 Jan-Apr;23(1):38-42.

6. Dan F, Tao L, Dong FS, Hui W, Peng D, Yan HH, et al. The association between smoking quantity and hypertension mediated by inflammation in Chinese current smokers. J Hyperten. 2013;31(9):1798-1805

7. Talukder MAH, Johnson WM, Varadharaj S, Lian J, Kearns PN, ElMahdy MA, et al. Chronic cigarette smoking causes hypertension, increased oxidative stress, impaired NO bioavailability, endothelial dysfunction, and cardiac remodeling in mice. Am J Physiol Heart Circul Physiol. 2011;300(1):388-396.

8. Jensen MT, Marott JL, Jensen GB. Elevated resting heart rate is associated with greater risk of cardiovascular and all-cause mortality in current and former smokers. Int J Cardiol. 2011;151(2):148-54.

9. Papathanasiou G, Georgakopoulos D, Papageorgiou E, Zerva E, Michalis L, Kalfakakou V. Effects of Smoking on Heart Rate at Rest and During Exercise, and on Heart Rate Recovery, in Young Adults. Hellenic J Cardiol. 2013; 54(3): 168-77

10. Gac P, Sobieszczańska M. Effects of cigarette smoke on Holter ECG recordings in patients with arterial hypertension. Part 1: Time domain parameters of heart rate variability. Environ Toxicol Pharmacol. 2014;37(1):404-13.

11. Chaudhery MK, Younus M, Bukhari MH. Smoking Trends Amongst Young Doctors of a Tertiary Care Hospital-Mayo Hospital, LahorePakistan. Ann King Edward Med Uni. 2011;17(1):14-17.

12. Ali IS, Yaqoob N, Fatima G, Iftekhar H, Abbas M. Pattern of smoking in medical students J Rawalpindi Med College. 2013;17(1):140143 .

13. Altaf M, Fatima K. Increasing obesity and its risk factors. Int J Endorsing Health Sci Res. 2013;1(1):21-4.

14. Nguyen T, Lau DCW. The Obesity Epidemic and Its Impact on Hypertension. Canad J Cardiol. May-June 2012; 28(3):326-333.

15. Ostchega Y, Hughes JP, Terry A, Fakhouri TH, Miller I. Abdominal Obesity, Body Mass Index, and Hypertension in US Adults: NHANES 2007-2010. Am J Hypertens. 2012;25(12):1271-1278.

16. Vaněčková I, Maletínská L, Behuliak M, Nagelová V, Zicha J, Kuneš J. Obesity-related hypertension: possible pathophysiological mechanisms. J Endocrinol. 2014 Dec;223(3):R63-78.

17. Movahed MR, Lee JZ, Lim WY, Hashemzadeh M, Hashemzadeh M. Strong independent association between obesity and essential hypertension. Clin Obes. 2016 Jun;6(3):189-92.

18. Flegal KM, Graubard BI, Williamson DF, Gail MH. Cause-specific excess deaths associated with underweight, overweight, and obesity. JAMA. 2007 Nov;298(17):2028-2037.

19. https://foh.psc.gov/NYCU/hypertension.asp

20. Bonita R, Duncan J, Truelsen T, Jackson RT, Beaglehole R. Passive smoking as well as active smoking increases the risk of acute stroke. Tobacco Control. 1999;8(2):156-160.

21. McElduff P, Dobson AJ, Jackson R, Beaglehole R, Heller RF, LayYee R. Coronary events and exposure to environmental tobacco smoke: a case-control study from Australia and New Zealand (1998). Tobacco Control. 1998; 7:41-46.

22. Sarah J. Patient. Problems caused by being underweight. Avalable from: https://patient.info/health/weight-loss-unintentional/features/ problems-caused-by-being-underweight.

23. Thinkhealth. Health Benefits of Walking: 20 Minutes a Day Makes a Difference; Oct 2016. Available from: http://thinkhealth.Priority health.com/health-benefits-of-walking-20-minutes-a-day-makes-a-dif ference

24. Ahmad R, Rashid UR, McDonald PW, Ahmad SW. Prevalence of cigarette smoking among young adults in Pakistan. JPMA. Nov 2008;58(11):597-601.

25. Chen Z, Peto R, Zhou M, Lona A, Smith M, Yang L, et al. Contrasting male and female trends in tobacco-attributed mortality in China: evidence from successive nationwide prospective cohort studies. Lancet. Oct 2015;386(10002):1447-56.

26. World Health Organization-Department of gender, women and health. WHO 10 facts on gender and tobacco;2010 Available from: www.who.int/gender/documents/10facts_gender_tobacco_en.pdf
27. Ogden CL, Carroll MD, Kit BK, Flegal KM. Prevalence of childhood and adult obesity in the United States, 2011-2012. JAMA. 2014 Feb;311(8):806-14

28. Sahoo K, Sahoo B, Choudhury AK, Sofi NY, Kumar R, Bhadoria AS. Childhood obesity: causes and consequences. J Fam Med Prim Care. 2015;4(2):187-192.

29. Lazzeri G, Azzolini E, Pammolli A, DeWet DR, Giacchi MV. Correlation between physical activity and sedentary behavior with healthy and unhealthy behaviors in Italy and Tuscan region: a cross sectional study. J Prev Med Hyg. 2013 Mar;54(1):41-48.

30. Almuhanna MA, Alsaif M, Alsaadi M, Almajwal A. Fast food intake and prevalence of obesity in school children in Riyadh City. Sudan J Paediatr. 2014;14(1):71-80

31. DeVenecia T, Lu M, Figueredo VM. Hypertension in young adults. Postgrad Med. 2016;128(2):201-7.

32. Battistoni A, Canichella F, Pignatelli G, Ferucci A, Tocci G, Volpe M. Hypertension in Young People: Epidemiology, Diagnostic Assessment and Therapeutic Approach. High Blood Press Cardiovasc Prev. 2015 Dec;22(4):381-8. 